\title{
Microbiological Analysis of Ice-cream Sold in Kathmandu Valley
}

\author{
KRISHTINA THAPA ${ }^{1 *}$ and SONU SHRESTHA ${ }^{1,2}$ \\ ${ }^{1}$ College of Applied Food and Dairy Technology, Minbhawan, Baneshwor, Kathmandu \\ ${ }^{2}$ Interpret Nepal, Thapathali, Kathmandu
}

Different types of ice cream samples were collected from three different local vendors of Kathmandu (i.e. Samakhusi, Jawalakhel and Chabahil) for the microbial examination. Study explored that the ice cream samples from Chabahil showed the presence of highest number of mesophilic microorganisms with an average of $2.16 \times 10 \mathrm{CFU} / \mathrm{ml}$ and $27.4 \mathrm{CFU} / 100 \mathrm{ml}$ of Coliform followed by samples collected from Jawalakhel and Samakhusi. The samples have been found to be contaminated with Coliforms (Enterobacter spp., Escherichia spp., Klebsiella spp., Citrobacter spp.), Salmonella (Salmonella typhi, Salmonella paratyphi, Salmonella enteritidis), Shigella (Shigella boydii, Shigella flexneri, Shigella sonnei, Shigella dysenteriae) and Staphylococcus aureus. These findings indicated that not only the unhygienic practices of handling by the vendors but also the carelessness of manufacturers during processing of ice creams.

Keywords: Ice cream, Salmonella and Shigella spp., Coliforms, Staphylococcus aureus

\section{Introduction}

Ice-cream is a frozen dairy food made by freezing a mix with agitation to incorporate air and insure uniformity and consistency (Panthi, 2008). The ingredients used in the preparation of mix are milk and milk products, sugar, dextrose, corn syrup in dry or liquid form, water and other optional ingredients with or without egg or egg product; food grade flavoring, color and stabilizers or emulsifiers are added in small quantities (Arbuckle, 1972; Panthi, 2008). Ice cream is one of the milk products which is perishable and get easily contaminated and spoiled. When ice cream is handled carelessly, it can act as the source of disease as milk. Being a milk based product with high nutrient value, almost neutral $\mathrm{pH}$ value and with long storage duration, ice cream act as the suitable media for microbial growth (Joshi et al., 2004; Robinson, 2005). The primary sources of contamination to ice cream is mostly water and raw milk whereas secondary sources could be flavoring agent, utensils and even human handling (Joshi et al., 2004). Although pasteurization, freezing and hardening steps in production can eliminate most of the microbial hazards but still numerous health hazards are persistent due to various conditions (Robinson, 1983). Many psychrophiles and psychrotolerants microorganisms like Listeria monocytogens, Staphylococcus aureus, Bacillus spp., Salmonella spp., Shigella spp., Pseudomonas spp., Camplyobacter spp., Brucella spp. and Coliform bacteria are usually found in ice-cream (Joshi et al., 2004). The ice cream made at low scale by unauthorized manufacturer and sold locally by local vendors in the streets are called local vendor ice cream. This ice cream is popular among people mainly children because they are comparatively very cheaper and easily available. These types of ice cream are generally popular during summer season. The manufacturers as being unauthorized, they are free from any kind of taxes, not bound by rules and regulation for quality maintenance which make them cheap but this factor also highlight how unsafe these

\footnotetext{
* Corresponding author, E-mail: kristuthapa15@gmail.com
}

products can be to the consumers. On the top, as children being the main consumers and also the main season for ice cream being summer and rainy season, the low microbiological quality of this kind of ice cream pose greater risk (Orallo et al., 1999).

The general objective of the study is to investigate the status of the microbial contamination in ice-cream sold by local vendors in three places of Kathmandu-Samakhusi, Jawalakhel and Chabahil, which ultimately will be helpful in preventing the possible health hazards that can occur by the consumption of contaminated ice-cream without being aware about its quality. The specific objectives of this study include to isolate, enumerate and identify the bacteria from local vendor ice cream and to compare the quality of local vendor ice cream in selected three places of Kathmandu valley.

\section{Materials and Methods}

Sample collection- The research started with collection of five samples from each of the selected three places of Kathmandu- Samakhusi, Jawalakhel and Chabahil in closed sterile insulated containers, transported to laboratory and immediately processed for microbiological analysis, which included determination of total number of total mesophiles and Coliforms and were then further analysed for identification of Coliforms, Salmonella spp., Staphylococcus spp. and Shigella spp. (FAO/WHO, 1973).

At first, the quarter strength Ringer's solution was used to serially dilute all ice cream samples, followed by procedures to have standard viable counts which includes pour plate technique on Tryptone Glucose yeast Extract agar (TGYA) for Mesophilic aerobic count; on Lactose broth tubes for Total Coliform count, inoculation on EMB agar followed by plating on Nutrient agar and identification by gram staining, catalase, oxidase tests; and on Manitol Salt Agar (MSA) for Staphylococcal count (Benson 1994; Joshi et al., 2004). Typical yellow colonies formed on the MSA were identified 
as Staphylococcus aureus by gram staining, catalase, oxidase, oxidative fermentative (O-F) and coagulase test and Salmonella spp. and Shigella spp. were identified by enrichment in Selenite F broth and further streaked on Xylose Lysine Deoxycholate (XLD) agar; the pink colonies with black centre formed on XLD agar were recognized as Salmonella spp. by gram staining (Benson 1994; Joshi et al., 2004).

\section{Results and Discussion}

From the above analysis, we observed that the samples collected from the three busy places of Kathmandu valley have presence of high number of microorganisms, including even the pathogenic ones. Chabahil sample showed the presence of high number of mesophilic microorganisms and Coliform followed by samples from Jawalakhel and Samakhusi area of Lalitpur \& Kathmandu respectively.

Table 1. Enumeration of organisms from Tryptone Glucose Yeast Extract Agar and Lactose Broth (MPN)

\begin{tabular}{|c|c|c|c|c|c|}
\hline S.N. & Sampling Site & Sample No. & Sample media used & Cfu/ml & Coliform/100ml \\
\hline \multirow[t]{10}{*}{1} & Samakhusi & Sample A & TGYA & $3 \times 10^{5}$ & \\
\hline & & & MPN & & 13 \\
\hline & & Sample B & TGYA & $4 \times 10^{5}$ & \\
\hline & & & MPN & & 16 \\
\hline & & Sample C & TGYA & $12 \times 10^{4}$ & \\
\hline & & & MPN & & 14 \\
\hline & & Sample D & TGYA & $14 \times 10^{4}$ & \\
\hline & & & MPN & & 16 \\
\hline & & Sample E & TGYA & $5 \times 10^{5}$ & \\
\hline & & & MPN & & 16 \\
\hline \multirow[t]{10}{*}{2} & Jawalakhel & Sample A & TGYA & $14 \times 10^{5}$ & \\
\hline & & & MPN & & 25 \\
\hline & & Sample B & TGYA & $6 \times 10^{5}$ & \\
\hline & & & MPN & & 25 \\
\hline & & Sample C & TGYA & $15 \times 10^{5}$ & \\
\hline & & & MPN & & 20 \\
\hline & & Sample D & TGYA & $2 \times 10^{6}$ & \\
\hline & & & MPN & & 20 \\
\hline & & Sample E & TGYA & $5 \times 10^{6}$ & \\
\hline & & & MPN & & 20 \\
\hline \multirow[t]{10}{*}{3} & Chabahil & Sample A & TGYA & $1 \times 10^{7}$ & \\
\hline & & & MPN & & 25 \\
\hline & & Sample B & TGYA & $2 \times 10^{6}$ & \\
\hline & & & MPN & & 31 \\
\hline & & Sample C & TGYA & $4 \times 10^{6}$ & \\
\hline & & & MPN & & 31 \\
\hline & & Sample D & TGYA & $9 \times 10^{7}$ & \\
\hline & & & MPN & & 25 \\
\hline & & Sample E & TGYA & $2 \times 10^{6}$ & \\
\hline & & & MPN & & 25 \\
\hline
\end{tabular}

Table 2. Organisms identified from Lactose Broth and XLD

\begin{tabular}{ll}
\hline Media used & Organisms Identified \\
\hline Lactose broth & Enterobacter spp. Citrobacter spp., Escherichia spp., Klebsiella spp. \\
XLD (Xylose Lysine & Salmonella typhi, Salmonella paratyphi, Shigell boydii, Shigella flexneri, \\
Deoxychocolate Agar) & Salmonella enteritidis, Shigella sonnei and Shigella dysenteriae
\end{tabular}


Escherichia spp. and Salmonella paratyphi were the two common microorganisms in all the samples collected. Staphylococcus aureus was detected in almost all the collected samples. Not only the poor personal hygiene and polluted environment increases the contamination of these ice creams; manufacturing of these ice creams as done by unauthorized manufacturers gives no assurance of maintenance of quality of ice cream. Escherichia spp. being the common microorganisms isolated from the collected samples, it indicates towards the fecal contamination through the hands of the sellers, containers, unhygienic environment and raw materials itself. The untreated water and sewages can act as the major source of coliform (Joshi et al., 2004; De 2008). Colifroms normally get destroyed during proper heat treatment of milk but can survive in the case of inefficient heat treatment or can enter food by unhygienic practices (De, 2008). The detection of Salmonella typhi and Salmonella paratyphi are the major concern as these can cause Salmonellosis. The efficient production method could also be the main reason behind this.

The detection of Stapylococcus aureus in almost all the samples indicate towards lack of maintenance of personal hygiene during the production and handling. This pathogen is wide spread in air, dust, water etc as well as found in nasal cavity, skin (especially hands), hair, throat discharge, wounds etc (Robinson, 1983). With vendors seen to be careless about the personal hygiene like spitting around, playing with hair, touching hair, non hand washing practices after toilet, the contamination of ice cream with Stapylococcus aureus is seen to be very high.

The high counts of pathogenic microorganisms obtained by the result clearly indicate the poor microbiological quality of the ice sold in the streets of Kathmandu.

\section{Conclusion}

The detection of pathogenic microorganisms in local vendor ice cream samples conclude that the environment in which the ice cream is sold, the personal hygiene of vendors along with careless from the unauthorized manufacturers of ice cream products are together contributing to its low microbiological quality and are therefore not fit for consumption. Its popularity among consumers for being cheap and easily available is increasing threat on human health. Therefore there is need of strict regulations from Government and awareness campaign among both the vendors and consumers.

\section{References}

Arbuckle W. S. (1972). Ice cream, 2 edn, Avi Publishing Company Inc., Westport, Connecticut.

Benson H. J. (1994). Microbiological applications: A laboratory manual in general microbiology, 6 edn, WM. C. Brown Company Publishers, Dubuque, Iowa.

De S. (2008). Outlines of Dairy Technology, 27 edn, Oxford University Press, Delhi, India.

FAO/WHO (1973). Joint FAO/WHO Food Standards Programme Codex Alimentarius Commission FAO/ WHO Committee of Government Experts on the Code of Principles Concerning Milk and Milk Products 1973, Code of principles concerning milk and milk products, international standards and standard methods of sampling and analysis for milk products, Food and Agriculture Organization of the United Nations, World Health Organization, Rome.

Joshi D., Shah P., Manandhar S., Sharma S. and Banmali P. (2004). Microbial Quality of Ice cream sold in Kathmandu. J. of Nepal Health Res. Council, vol. 2, no. 2.

APHA, (1992). Standard methods for the examination of dairy products, 16 edn, Marshall R. (Ed.) T. American Public Health Association, Washington, D.C.

Marth E. H. and Steele J. L. (2001). Applied Dairy Microbiology, CRC Press, Available at: <http://search. ebscohost.com/login.aspx? direct $=$ true $\& d b=n l e b k \& A N$ $=68195 \&$ site $=$ ehost-live $>$.

Orallo G. O., Pangan A. H. and Canbrera E. C. (1999). Micobiological analysis of ice cream produced by big scale and small scale manufactures in Metro Manila. Phil. J. Microbiol. Infect Dis., 28: 99-101.

Panthi R. R. (2008). Advances in ice cream science and technology', College of Applied Food and Dairy Technology.

Robinson R. K. (1983). Dairy Microbiology, 2 edn, vol. 1 and 2, Applied Science Publishers, London.

Robinson R. K. (2005). Dairy Microbiology Handbook: The Microbiology of Milk and Milk Products, Wiley Publishers. 